\title{
Research on the Transformation of Public Library Service Mode Based on the "Internet Plus" Model
}

\author{
Yong Zhu, Dapeng Zhou \\ Gongqing College, Nanchang University, Gongqing City, Jiangxi Province, 332020, China
}

Keywords: "Internet Plus"; Public Library; Service Mode; Transformation; Innovation

\begin{abstract}
The arrival of the "Internet Plus" era not only creates a new impetus for the development of public libraries, but also provides an unprecedented opportunity for the innovation and development of the whole public library. However, it also brings challenges to the inherent service idea and service mode of public library, so it is very urgent and necessary to think about the service innovation of public library under the environment of "Internet Plus". Based on the author's study and practical experience, this paper first analyzed the traditional service mode of public library, then studied the "Internet Plus" reader service model, and finally put forward the ways of service mode innovation.
\end{abstract}

\section{Introduction}

In March 5th 2015, Premier Li Keqiang put forward the "Internet Plus" action plan for the first time in the government work report, raising the "Internet Plus" to the national strategic level. In March 5th 2015, Premier Li Keqiang put forward the "Internet Plus" action plan for the first time in the government work report, raising the "Internet Plus" to the national strategic level. As the place of citizens' lifelong education and the important position of reading for all people, the public library is the core part of the public cultural service system. It undertakes the important task to protect the citizens' basic knowledge rights and interests and to enrich the people's spiritual and cultural life, so its construction and development have been attached great importance to all the time.

\section{Traditional Service Mode of Public Library}

The traditional service mode of public library provides service to readers with abundant Collection Resources. Several concepts in the process of service are simply divided into resources, channels, readers, librarians. The service flow can be summarized as follows: the readers retrieve the resources provided by the library through the retrieval route, and use the acquisition route to know the required information. The librarian is involved in the entire process of answering readers' advice, helping to retrieve documents, processing and sorting out resources, transferring documents, and borrowing to help readers obtain resources (see Fig.1).

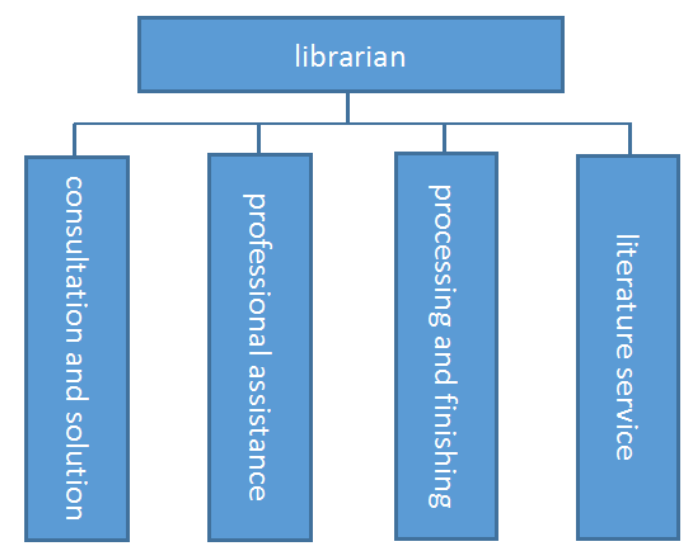

Fig.1 The Traditional Service Mode of Public Library 


\section{3. "Internet Plus" Reader Service Model}

Internet of things, mobile Internet and other information technology provide a good opportunity and reference for library reader service model innovation. Based on this, the author tries to put forward the "Internet Plus" reader service model. As can be seen from figure 2, the "Internet Plus" reader service model is still composed of "resources, channels, readers and librarians". However, due to the intervention of information technology, the "Internet Plus" reader service mode is different from the traditional reader service mode. Except that the reader and its needs can not be changed, the other elements are different.

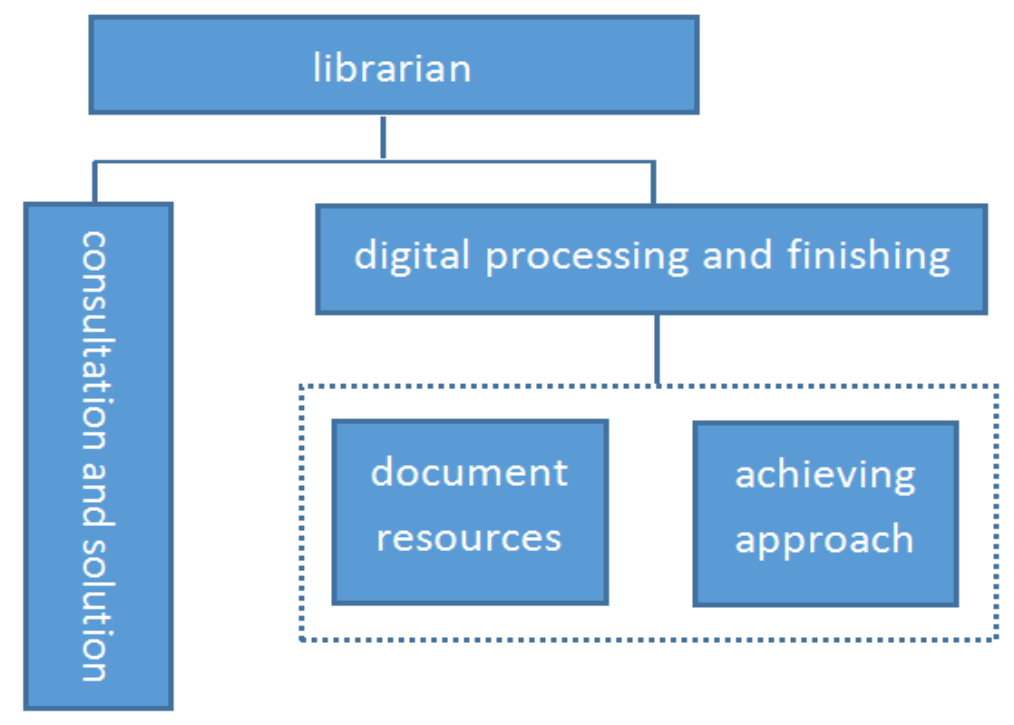

Fig.2 The "Internet Plus" reader service model

\subsection{Integration and utilization of intellectual literature resources}

The library can integrate all information resources, including documents of various carriers, metadata in all kinds of databases, and endow them with "identity information" according to the unified data standard. In the integration of library resources, the first step is to process the original resources digitally. Although the traditional libraries pay more and more attention to the development of digital resources, the physical resources still occupy a large proportion of the collection resources. Readers use the library to borrow paper books, periodicals and so on. Secondly, this kind of digital information is integrated with the existing digital resources to form a complete library of digital resources in the public library. Readers can not only achieve cross-database retrieval, but also cross-carrier and cross-platform knowledge retrieval. At the same time, readers can use mobile terminal or PC to realize the reading for each resource information in the library, and select the required information to obtain.

\subsection{Providing a variety of literature retrieval}

The "Internet Plus" reader service model has established a unified knowledge retrieval platform for libraries. Readers can access the knowledge retrieval platform and carry out literature retrieval through PC and mobile terminals. With only one retrieval, the reader can find out all kinds of documents related to key words, avoiding multiple searches, and the repeatability and complexity of retrieval on different platforms. In addition, by developing the mobile APP program of the library, readers can use the mobile terminal to install the corresponding APP to realize the retrieval and acquisition of resources. In view of the difference between mobile terminals such as mobile devices and PC terminals, it is necessary to process the digital document format adaptively, so that readers can get the optimal experience no matter by which way they browse the resources.

\subsection{Changing the service mode of librarians}

In the traditional reader service mode, the librarian, in addition to undertaking the information service, also needs to answer the reader's consultation, help the reader to find the specific book 
position, and carry out the work of borrowing and returning the books and periodicals. The "Internet Plus" service mode applies "RFID" in the Internet of things technology to the information collection of paper documents. Readers can use radio frequency devices to find the required book location to borrow and return. In this way, the librarian will greatly reduce the workload and improve the efficiency of the work. At the same time, the librarian can devote his energy to solving the reader's professional reference service or wisdom service.

\subsection{Collecting reader information for big data analysis}

In addition to integrating all kinds of library resources information, the collection of readers' individual behavior information (such as borrowing history, participation in activities, retrieval direction, etc.) is also very important. The information of readers' reading service needs, models, habits and hobbies are the basis and effective evaluation standard for the construction of library reader information big data. Therefore, by using the Internet of things, the reader's personal information, hobbies, reading needs and so on are stored in the radio frequency information of the reader's card when the reader first goes to the library to process the reader's card.

\section{The Ways of Service Mode Innovation}

\subsection{To ensure the information security of readers}

In the era of Internet, every industry is faced with a very important and difficult problem information security. When facing readers as a user group, libraries need to collect a large number of personal behavior information for processing, to complete the personalized service, Therefore, it will be an important problem for libraries to solve in the environment of "Internet Plus" to do a good job of ensuring the security of readers' information.

\subsection{To develop a new service model for resource information standards}

For each unit of information in the resource, special information identification is given, similar to the unique identifier system, which is convenient for the reader to carry on the unified retrieval, so it is necessary to establish the corresponding standard for the information of the resource. Each unit information should include the fixed field information, and according to the corresponding standard, each document or digital resource should be processed to form a complete resource bank. When we make the standard, we need to take into account the differences of different document types and carriers. We should realize the diversification of document types in the resource bank and ensure that the resource data processing can be based on the standards at the same time.

\subsection{To increase investment in software and hardware development}

Internet of things, cloud computing and other technologies cannot be separated from the development of software and hardware construction, which also requires a lot of investment. For example, in the use of the Internet of things, devices in the perception layer are expensive. In terms of communications technology, the coverage of wireless networks and the use of cellular communication technologies require significant funding. At the same time, the development of library technology also needs the investment of manpower and material resources. As a public service unit, libraries are supported by governments at all levels of financial support. Due to the difference of economic situation and cultural importance, the degree of government investment in library is different. Lack of funds will become an obstacle to the application of the Internet of things in libraries. How to apply for adequate financial support is also an important issue for public libraries to consider.

\subsection{Speed up the cultivation of intelligent librarians}

In the "Internet Plus" reader service model, the duties of the librarian changed accordingly. It is no longer necessary for librarians to simply borrow and return documents and collate physical documents, but to digitize the collection resources and to provide reference services for users. This kind of reference service is no longer a simple document transfer, but it needs to use data 
mining to analyze the information, which requires libraries to intensify the cultivation of intelligent librarians, combine the librarians' working skills, vocational education and professional training, and cultivate the librarians' quality in all directions and in various ways.

\section{Conclusions}

The use of mobile Internet, Internet of things, big data, cloud computing and other technologies make the service mode of the library gradually develop from traditional artificial service to intelligent service. Although, the realization of the "Internet Plus" reader service model also needs to solve the problems of information security, technology development, personnel literacy and so on, the author believes that with the continuous improvement of technology, more innovative service modes will appear in the intelligent library in the "Internet Plus" era.

\section{Acknowledgements}

Key Project of Art Science Planning in Jiangxi Province; Business process Reengineering of Public Libraries in Jiangxi Province (YG2014227)

\section{References}

[1] Xiang Honghua. Study on the innovation of library service under the thinking of "Internet Plus" [J]. Library work and Research, 2017, (04): 5-10.

[2] He Xiaolin, Liu Xiaoli. Research on the innovative path of Public Library Service under the thinking of "Internet Plus" [J]. Contemporary Library, 2016, (18): 59-63.

[3] Li Jiaxing, Wang Yuwei, Zhang Changliang. Study on the Mode of Library Innovation Service under the Environment of Internet[J]. Study on Library Science, 2016, (01): 31-36.

[4] Liu Xiaobin.Innovation of Service Mode of Public Library in the Environment of Internet [J]. Information Exploration, 2016, (01): 116-120.

[5] Zhang Xingge. On "public library Internet plus" era of service innovation[J]. Journal of Zhengzhou University of Light Industry (SOCIAL SCIENCE EDITION), 2017, (01): 31-37. 